\title{
Corpos invisíveis em Julio Cortázar: o não humano na esfera do matável
}

\author{
Hiandro Bastos da Silva ${ }^{1}$ \\ Lauro Roberto do Carmo Figueira ${ }^{2}$
}

Resumo: $O$ presente estudo visa dar enfoque aos corpos invisíveis à ordem jurídica na escrita de Julio Cortázar a partir da leitura do conto Carta a uma senhorita em Paris (1986). Com base nas discussões de Giorgio Agamben acerca do homo sacer - figura do direito romano arcaico insacrificável e, ao mesmo tempo, matável -, procura-se analisar, na narrativa de Cortázar, o modo como o não humano, assim classificado pela "máquina antropológica" (AGAMBEN, 2017, p. 51), adentra na esfera da matabilidade. Dessa forma, o homem recai no mesmo grau de vulnerabilidade do animal, desmantelando as fronteiras éticas existentes entre ambos, atestadas por Jacques Derrida (2002). Por consequência, compreende-se, com Gabriel Giorgi (2016), que a vida reconhecida como humana se torna cada vez mais difícil de se aferir na atualidade. Assim, além de se averiguar, na narrativa do prosador Cortázar, as políticas do contemporâneo atravessarem o corpo e a subjetividade do protagonista, subtraindo o seu valor, evidencia-se o animal demarcando o limiar desta realidade de exceção, em que a vida se faz matável.

Palavras-chave: Humano. Não humano. Homo sacer. Julio Cortázar.

filósofo argelino Jacques Derrida (1930-2004), no ensaio $O$ animal que logo sou (2002), aponta a matabilidade como traço característico que pesa sobre o animal na cultura ocidental - herança de uma tradição antropocêntrica. Consequentemente, permite-se que se subjugue

1 Mestrando em Literaturas Hispânicas pela Universidade Federal Fluminense (UFF). Graduado em Licenciatura em Letras Português (2021) pela Universidade Federal do Oeste do Pará (UFOPA). Foi voluntário no Grupo de Estudos e Formação Literária Litteris, assim como no Grupo de pesquisa, Estudos e Intervenção em Leitura, Escrita e Literatura na Escola Lelit, ambos vinculados à UFOPA, entre o ano de 2017 e 2018. Tem atuado como membro do Grupo de Pesquisa Estudos Literários e Memória de Expressão Amazônica (2021). Atualmente, dedica-se às linhas de pesquisa que focalizam o Realismo Maravilhoso, Estudos sobre o Neofantástico e as Políticas do Contemporâneo em suas diversas relações com a Literatura Latino-americana.

2 Professor Associado da Universidade Federal do Oeste do Pará. 
e aniquile o corpo não humano, haja vista a autoridade que o humano detém sobre ele, pois cerceia o seu direito à vida. Contudo, no ordenamento político, o aspecto matável se estende também ao corpo humano, quando vinculado a determinadas formas de indigência, conforme descrevem os estudos de Giorgio Agamben (2007, 2015, 2017).

No cenáriocontemporâneo, desenvolvendoasperspectivas deDerrida e Agamben, encontram-se, na condição adjacente ao animal, mulheres inseridas em contextos de extrema opressão patriarcal, jovens negros em favelas, refugiados no campo de Moria, presidiários de Guantánamo, entre outros grupos, caracterizados pela completa vulnerabilidade e abandono. Como resultado, homem e animal se encerram na complexa esfera do matável, espaço de exceção onde a "máquina antropológica do humanismo" (AGAMBEN, 2017, p. 51), mecanismo que atualiza arbitrariamente o conceito de humano, investe violentamente contra os corpos que não se ajustam ao seu ideal de humano.

Para analisar as figuras invisíveis à ordem jurídica, Agamben recorre ao conceito de homo sacer, um espectro ambíguo do direito romano arcaico - insacrificável e, ao mesmo tempo, matável. Esse conceito, abordado à luz da contemporaneidade, corresponde aos corpos viventes já considerados mortos, segundo o imaginário estatal. Sob este entendimento, o filósofo italiano sonda a esfera em que a vida se configura absolutamente matável, circunstância à qual está atrelado o protagonista do conto Carta a uma senhorita em Paris (1986), do escritor argentino Julio Cortázar (1914-1984).

Atentando-se a tais discussões, realiza-se uma leitura de Carta $a$ uma senhorita em Paris com o intuito de evidenciar a presença do homo sacer no conto de Cortázar. Essa situação decorre por obra da contiguidade entre homem e animal, em uma trama epistolar, na qual o "devir-animal" (DELEUZE; GUATTARI, 1997, p. 1.731), vivenciado pelo protagonista, o faz regurgitar coelhos. À vista disso, o animal, na narrativa cortaziana, “[...] começa a funcionar como contínuo orgânico, afetivo, material e político 
com o humano [...]" (GIORGI, 2016, p. 8), não somente se projetando sobre a psique tumultuada desse angustiado personagem, mas também demarcando os territórios onde a vida se desvincula do seu valor.

\section{O homo sacer em Carta a uma senhorita em Paris}

Proveniente das complexas estruturas jurídicas da Antiguidade, o homo sacer, conceito cujo nome intitula o ensaio de Agamben, publicado em 1995, relacionava-se ao indivíduo que, após o cometimento de determinado delito, sofria a revogação de todos os seus direitos e prerrogativas de cidadão. Desse modo, tornar-se-ia vulnerável a qualquer tipo de violência, tal qual o animal na cultura ocidental. Logo, o homo sacer podia ser morto sem configurar homicídio, decorrente da sacralidade da sua vida, pois: “[...] pertence ao Deus na forma da insacrificabilidade e é incluído na comunidade na forma da matabilidade. A vida insacrificável e, todavia, matável, é a vida sacra." (AGAMBEN, 2007, p. 90). Originariamente, na definição romana, o homo sacer residia em uma dupla exclusão, tanto da jurisdição humana quanto da jurisdição divina. Era-lhe imposta a impossibilidade de exercer a política na sociedade e também de constituirse um sacrifício, segundo as formas prescritas de rito.

Devido à anulação de direitos e prerrogativas, resta ao homo sacer somente a vida nua, natural e desqualificada, incluída no ordenamento político na forma de exclusão. A sua vida entra para os cálculos do poder como alvo de violência e "privada de todo valor político" (AGAMBEN, 2007, p. 139). Relaciona-se à vida do homo sacer o termo grego zoé, utilizado por Agamben em Meios sem fim: notas sobre a política (1996) - o vocábulo alude à vida desqualificada e irreconhecível, passível de ser abandonada. Esse sentido se opõe ao do vocábulo bíos, também utilizado na obra supracitada, que alude à vida qualificada e reconhecível, passível de ser protegida. 
No repertório da zoé, a vida humana não se distingue da vida não humana, levando a concluir que, ao encaminhar o homem para a margem do ordenamento político, lá, ele encontrará o animal invariavelmente. Assim, permite-se averiguar, na narrativa, o homo sacer como um ser indistinto entre dois universos; o humano e o não humano.

Uma vez superado o aspecto religioso do homo sacer na pósmodernidade, mantido, então, pela noção do sacrifício, que conferia ao conceito o caráter de mitologema, pode-se interpretá-lo como fenômeno jurídico-político. Para isso, encaminham-se as reflexões de Agamben, desenvolvidas no sentido de constatar em qual momento a vida do homem se faz aniquilável pela ordem soberana e determinar a natureza desta condição de abandono:

Aquilo que define a condição do homo sacer, então, não é tanto a pretensa ambivalência originária da sacralidade que lhe é inerente, quanto, sobretudo, o caráter particular da dupla exclusão em que se encontra preso e da violência a qual se encontra exposto. Esta violência - a morte insancionável que qualquer urn pode cometer em relação a ele - não é classificável nem como sacrifício e nem como homicídio, nem como execução de uma condenação e nem como sacrilégio. (AGAMBEN, 2007, p. 90).

Assim, a situação do indivíduo, deslocado para o repertório sacer, apresenta-se paradoxal, em consequência da exclusão realizada por meio da sua inclusão nas gramáticas da violência. No entanto, deve-se pontuar que "Não se poderia dizer de modo mais claro que o fundamento primeiro do poder político é uma vida absolutamente matável, que se politiza através de sua própria matabilidade" (AGAMBEN, 2007, p. 96). Ou seja, a vida nua do homo sacer, como instância política originária, é indispensável ao domínio soberano. Doravante, o poder se constitui soberano pela possibilidade de aniquilamento da vida nua, sendo esta a condição autêntica de participação 
na sociedade. Todo indivíduo é, portanto, potencialmente homo sacer.

Nas produções literárias que abordam a questão animal, tornou-se comum observar o não humano demarcando os territórios onde se abre a esfera do matável. Essa esfera representa a queda do ideal civilizatório do humanismo, haja vista que, nela, o "especificamente humano" (GIORGI, 2016, p. 26) deixa de ser o índice daquilo que deve ser preservado e passa a estar completamente exposto à barbárie. Por conseguinte, vida humana e vida animal entrecruzam-se por intermédio da matabilidade. Tais apontamentos podem ser verificados em Carta a uma senhorita em Paris, pois as circunstâncias narradas no conto comunicam sobre o espaço de exceção da máquina antropológica. Na história de Cortázar, a anulação da existência do protagonista é posta em ação pelo esvaziamento das potências que a sustentam e dos significantes que a determinam.

Neste ponto, faz-se necessário recordar o enredo que Cortázar coloca em curso no texto: a redação de uma carta pelo protagonista (narrador autodiegético), na qual apresenta uma história aparentemente ordinária, de efeito pouco dinâmico, mas com ocorrências insólitas. Uma mudança espacial; este é o ponto de partida para o enovelamento da intriga, ou quando os eventos cruciais se desenrolam $O$ protagonista, a pedido de sua amiga, Andrée, desloca-se do campo, onde vivia confortavelmente, e parte em direção à metrópole, Buenos Aires. Ali, instala-se no apartamento da destinatária da carta, missiva sobre a qual se opera toda a narrativa. Andrée se encontra fora do país por razões não esclarecidas pelo narrador. Assim, configura-se a situação inicial do conto, com o protagonista no papel de proprietário temporário da casa na avenida Suipacha. Entretanto, no desfecho da história, ele se verá destituído tanto do papel de proprietário temporário da casa quanto de proprietário temporário do seu próprio corpo.

A história captura a perspectiva da vida nua do homo sacer, reinscrevendo-a junto à estética instigante do Fantástico. O conto, valendo- 
se dos procedimentos ficcionais direcionados ao "artefato animal" (GIORGI, 2016, p. 12), coloca em marcha a máquina narrativa do prosador argentino, o que culmina na irreparável degradação da vida do protagonista, elevada a um estado de plena indiferença frente à morte. O personagem principal, ao confessar que "De quando em quando me acontece vomitar um coelhinho [...]” (CORTÁZAR, 1986, p. 23), aparenta julgar-se culpado de uma transgressão imperdoável contra a ordem instituída, no apartamento da amiga Andrée, lugar onde mesmo o menor item pertence a uma severa cadeia organizacional:

Mexer nessa tacinha altera o jogo de relações de toda a casa, de um objeto com outro, de cada momento de sua alma com a alma inteira da casa e sua distante moradora. E eu não posso aproximar os dedos de um livro, ajustar de leve o cone de luz de um lampião, abrir a tampa da caixa de música, sem que um sentimento de ultraje e desafio me passe pelos olhos como um bando de pardais. (CORTÁZAR, 1986, p. 22).

Logo, o feérico hábito do novo residente de Suipacha se converte em uma falta grave mediante a distribuição biopolítica que impera naquele espaço. Consequentemente, a vida do protagonista se torna indesejada ao longo do enredo, subtraindo-se de seu valor ao ponto de fazer-se "indigna de ser vivida" (AGAMBEN, 2007, p. 128). É, portanto, desse modo que o personagem de Cortázar desponta como homo sacer, traçando em si próprio o estigma do matável.

Quanto à vertiginosa proximidade entre homem e animal estabelecida no conto, salta aos olhos a arbitrariedade com a qual o protagonista age frente à vida dos coelhos. Suas estratégias para manter os animais ocultos são definidas não no intuito de protegê-los, mas, sim, de garantir êxito no disciplinamento deles. Em decorrência dessa situação, o personagem flerta constantemente com o axioma soberano 'fazer morrer': 
Decidi, contudo, matar o coelhinho mal nascesse. $\mathrm{Eu}$ viveria quatro meses em sua casa: quatro, talvez, com sorte, três - colheradas de álcool no focinho. (Você sabe que a misericórdia permite matar instantaneamente um coelhinho dando-lhe de beber uma colherada de álcool? Sua carne então sabe melhor, dizem, embora eu ... Três ou quatro colheradas de álcool, em seguida o banheiro ou um pacote se somando ao lixo. (CORTÁZAR, 1986, p. 25).

A inclinação inicial do protagonista comprova a irrelevância da existência dos pequenos viventes, pois a decisão entre vida ou morte é ponderada friamente pelo autor da carta, sem nenhuma reserva, de fato, pelo radicalmente outro. Nesse arranjo, os coelhos são anunciados como uma unidade sacer, ou seja, absolutamente matáveis, desde o início da narrativa. Logo, o personagem central representa a decisão soberana, um elemento ativo de tirania. Entretanto, após afirmar: "Compreendi que não podia matá-lo [...]" (CORTÁZAR, 1986, p. 25), ele perde as rédeas da situação, passando a ser alvo da mesma opressão que aflige seus semelhantes não humanos.

Ao passo que as regurgitações se intesificam, o protagonista sente sua existência declinar, como se estivesse sendo guiado para o abismo do esquecimento, destino certo de todo sacer. Essa espécie de 'crime', o qual ele tenta reparar, consome-o de modo atroz e retira-lhe lentamente o direito de participação social. No entanto, alegando que vomitar coelhos "Não é razão para não viver em qualquer casa, não é razão para que a gente deva se envergonhar e estar isolado e andar se calando [...]" (CORTÁZAR, 1986, p. 23), o personagem busca convencer-se de que a sua transgressão não é tão grave como aparenta. Presumivelmente, a assertiva não se sustenta por muito tempo. Adiante, na narrativa, então, nota-se a elevação do seu tormento, decorrente das exaustivas medidas que empreende para ocultar a sua infâmia: 
Verdade que parece impossível; nem Sara acreditaria. Porque Sara não desconfia de nada, e o fato de que não desconfie de nada se deve a minha horrível tarefa, uma tarefa que consome meus dias e minhas noites num só golpe de rastelo e vai me queimando por dentro e endurecendo como aquela estrela-do-mar que você pôs sobre a banheira e que a cada banho parece encher o corpo da gente de sal e açoites do sol e grandes rumores da profundidade. (CORTÁZAR, 1986, p. 26-27).

Tal tarefa, a que se dedica arduamente o protagonista, inviabiliza que ele promova interações sociais e se exerça como cidadão da metrópole. Assim, antecipando-se a prováveis represálias que a revelação de seu hábito incomum acarretaria, o protagonista opta pelo confinamento no apartamento de Andrée. Em verdade, porém, a exclusão do protagonista implica a sua inclusão nas gramáticas da violência, consumadas em seu próprio corpo. Desse modo, ele evita contato com o mundo ao qual não pertence:

Agora me chamam ao telefone, são os amigos que se inquietam com minhas noites recolhidas, é Luís que me convida a caminhar ou Jorge que reservou entradas para um concerto. Quase não me atrevo a lhes dizer que não, invento prolongadas e ineficazes histórias de má saúde, de traduções atrasadas, de evasão. E quando retorno e subo de elevador aquela passagem, entre o primeiro e o segundo andar - renovo noite a noite irremediavelmente a vã esperança de que não seja verdade. (CORTÁZAR, 1986, p. 28-29).

A peculiar contiguidade homem/animal, em tela no conto, desordena as distribuições biopolíticas simbolizadas pela casa de Andrée, além de tornar o protagonista um alvo da máquina antropológica. A emergência dos coelhos constitui uma brusca ruptura da ordem vigente, atribuindo 
ao personagem a imagem de 'inimigo', o culpado pelo caos, que deve ser eliminado. Por consequência, furta-se morosamente a legitimidade da vida do protagonista, de maneira que a sua morte seja considerada praticamente um consenso para a preservação das estruturas formais da realidade:

Há esta sacada sobre Suipacha cheia de aurora, os primeiros sons da cidade. Não acredito que lhes seja difícil juntar onze coelhinhos salpicados sobre os paralelepípedos, talvez nem os notem, atarefados com o outro corpo que convém levar logo, antes que passem os primeiros colegiais. (CORTÁZAR, 1986, p. 32).

Como artifício do poder soberano, o personagem de Cortázar se sente impulsionado a cometer autoagressão, eliminando a si mesmo e aos coelhos, o que consolida a narrativa como uma carta de suicídio. Nessa conjuntura, então, homem e animal perecem na esfera da matabilidade por ação dos seus destinos trágicos, que não representam perda alguma para o universo biopolítico. O excerto final, "convém levar logo, antes que passem os primeiros colegiais" (CORTÁZAR, 1986, p. 32), reforça o aspecto sacer do protagonista, cuja morte não causará a mínima comoção, mas apenas o incômodo de se ter um cadáver estirado na rua à luz do dia. Isso comprova a irrelevância de uma vida desqualificada, que pouco se distingue dos “onze coelhinhos salpicados sobre os paralelepípedos" (CORTÁZAR, 1986, p. 32).

\section{A vida indigna no horizonte biopolítico contemporâneo}

O tema da vida indigna de ser vivida, ou vida que não merece viver, recebe especial atenção de Agamben na terceira parte da sua obra Homo Sacer: o Poder Soberano e a Vida Nua (2007). No segmento em questão, o filósofo italiano discorre sobre esta categoria política espoliada de seu 
valor, detendo-se ao exame do ensaio A autorização do aniquilamento da vida indigna de ser vivida, publicado em 1920, de autoria do jurista alemão Karl Binding (1841-1920) e do seu compatriota psiquiatra Alfred Hoche (1865-1943). Nessa reflexão ensaística, ambos defendem a legitimidade da eutanásia no cenário jurídico europeu, abordando a impunibilidade do suicídio "[...] como expressão de uma soberania do homem vivente sobre a própria existência [...]" (AGAMBEN, 2007, p. 143). O poder do homem sobre a própria vida se assemelharia, então, ao poder do Estado sobre a população, segundo a perspectiva dos autores. Perante a ótica da soberania individual, promove-se o processo de eliminação da vida sem valor na biopolítica moderna.

A necessidade de legitimizar o aniquilamento da existência subtraída do seu valor configura a estratégia fundamental da biopolítica. Contudo, os autores alemães, sem talvez considerar tal implicação, ou imaginar a dimensão de que o seu trabalho representaria para o Direito, a Filosofia, a Ética, a Política e a Teoria do Estado, manifestam sua simpatia para com a prática da eutanásia, indagando se: “[...] existem vidas humanas que perderam a tal ponto a qualidade de bem jurídico, que a sua continuidade, tanto para o portador da vida como para a sociedade, perdeu permanentemente todo o valor?" (BINDING; HOCHE, p. 27 apud AGAMBEN, 2007, p. 144). Assim, de acordo com Agamben, os autores encontram a resposta para o questionamento tanto na figura dos “incuravelmente perdidos" (AGAMBEN, 2007, p. 145), indivíduos tornados inválidos, devido a doenças ou acidentes, quanto na figura dos “idiotas incuráveis" (AGAMBEN, 2007, p. 145), indivíduos acometidos de doenças genéticas. Ambos os grupos apresentam uma imagem deturpada do que se traduz como 'humano', segundo os dois estudiosos alemães citados.

Alinhando, então, o conceito da vida indigna de ser vivida ao horizonte biopolítico contemporâneo, emergirão, das entranhas do 
ordenamento político, outros grupos sem valor, semelhantes aos referidos acima. Para os corpos viventes deixados na condição de indigência, não consta razão alguma para o veto da morte. Interliga-se a este contexto a acepção do homo sacer, resultante do processo de desvalorização da vida:

Mais interessante, em nossa perspectiva, é o fato de que a soberania do homem vivente sobre a sua vida corresponda imediatamente a fixação de um limiar além do qual a vida cessa de ter valor jurídico e pode, portanto, ser morta sem que se cometa homicídio. A nova categoria jurídica de "vida sem valor" (ou "indigna de ser vivida") corresponde ponto por ponto, ainda que em uma direção pelo menos aparentemente diversa, a vida nua do homo sacer [...]. (AGAMBEN, 2007, p. 146).

Essa ponderação de Agamben aprofunda mais o entendimento sobre a perspectiva relativa à indissociabilidade entre a vida sem valor e a vida nua do homo sacer, que se enlaçam mutuamente, não obstante derivadas de estruturas complexas e distintas. Nesse bojo de relações, a autorização do aniquilamento da vida indigna de ser vivida colide com a impossibilidade do assassinato de um homo sacer caracterizar homicídio, devido a sua natureza “insacrificável e, todavia, matável” (AGAMBEN, 2007, p. 90). Os dois casos constituem a esfera do matável, entretanto, sob circunstâncias diferentes: enquanto a vida indigna de ser vivida reivindica o suicídio para a execução da sua soberania individual, o poder soberano reivindica a vida do homo sacer. Agamben ajusta a sua ótica, contudo, ao perceber que a decisão soberana não se restringe ao espaço jurídico. Ela avança para o interior de cada vida:

E como se toda valorização e toda "politização" da vida (como está implícita, no fundo, na soberania do indivíduo sobre a sua própria existência) implicasse 
necessariamente uma nova decisão sobre o limiar além do qual a vida cessa de ser politicamente relevante, e então somente "vida sacra" e, como tal, pode ser impunemente eliminada. (AGAMBEN, 2007, p. 146).

Compreende-se, nesse debate, a real dimensão do poder soberano, estendida para além das fronteiras do ordenamento político. Esse poder se realiza alternado entre exterioridade e interioridade, ou concomitantemente. Tal movimento do poder soberano não é considerado incomum, haja vista que o pensamento biopolítico se difunde irremediavelmente no tecido do contemporâneo, requisitando a preservação do bando soberano, bem como a imediata eliminação das vidas que não merecem viver:

Toda sociedade fixa este limite, toda sociedade mesmo a mais moderna - decide quais sejam os seus "homens sacros". Impossível, aliás, que este limite, do qual depende a politização e a exceptio da vida natural na ordem jurídica estatal não tenha feito mais do que alargar-se na história do Ocidente e passe hoje - no novo horizonte biopolítico dos estados de soberania nacional - necessariamente ao interior de toda vida humana e de todo cidadão. (AGAMBEN, 2007, p. 146).

Em 1940, o Terceiro Reich inaugurou o projeto de eliminação da vida indigna de ser vivida, indiretamente associado às ideias de Binding e Hoche, cujo alvo foram os doentes mentais incuráveis e outros indesejáveis. A esta operação se deu o nome de Euthanasie-Programm filr unheilharen Kranken, promovida na pequena cidade alemã de Grafeneck, com a suposta justificativa humanitária. Tal projeto não possuiu um formato legal na gestão germânica da época, todavia, agregou-se perfeitamente ao ideal ariano e às políticas adotadas naquele momento. Mantendo-se ativo por 
quinze meses, o Euthanasie-Programm agenciou o genocídio de milhares de vidas julgadas sem valor. Assim descreve Agamben:

O instituto recebia a cada dia cerca de setenta pessoas (em idade variável de 6 a 93 anos), escolhidas entre os doentes mentais incuráveis espalhados pelos vários manicômios alemães. Os doutores Schumann e Baumhardt, que tinham a responsabilidade do programa em Grafeneck, submetiam as doentes a uma consulta sumária e decidiam se estes apresentavam os requisitos exigidos pelo programa. Na maior parte dos casos, os doentes eram mortos nas 24 horas seguintes a chegada à Grafeneck; primeiro era lhes ministrada uma dose de $2 \mathrm{ml}$ de Morphiurn-Eseopolarnina e depois eram introduzidos em uma câmara de gás. Em outros institutos (como, por exemplo, em Hadamcr), os doentes eram mortos com uma forte dose de Luminal, Veronal e Morphiurn. Calcula-se que deste modo foram eliminadas cerca de sessenta mil pessoas. (AGAMBEN, 2007, p. 147-148).

Esse registro comunica sobre a nova incumbência biopolítica do Estado nacional-socialista: a de delegar ao poder soberano a decisão sobre a vida indigna de viver. Encontrou-se justamente nesse fato maior motivação para a adesão do programa de eutanásia na vigência do Terceiro Reich, haja vista que os princípios eugênicos, aos quais o programa teoricamente iria beneficiar, já estavam sendo seguidos à risca. As políticas de saúde realizavam a prevenção contra doenças, além da proteção da saúde hereditária. Nessa conjuntura, a autorização do aniquilamento da vida indigna de ser vivida não correspondeu à tentativa de resguardar a integridade biológica da população, mas, sim, separar completamente do corpo genético da nação os fenótipos aos quais se associavam comportamentos considerados nocivos.

Permite-se reconhecer, portanto, que há muito a vida indigna de ser vivida se emancipou do sentido ético, antes imanente a ela, pois não “[...] concerne às expectativas e legítimos desejos do indivíduo" (AGAMBEN, 
2007, p. 147-148). Isto é, tanto o discernimento cabível a cada um para julgar o valor da sua existência, quanto à decisão de lhe pôr fim não estão mais na tutela do homem, o que denuncia o arranjo biopolítico estabelecido a partir da modernidade. A vida indigna evidencia, agora, uma categoria política, a qual “[...] está em questão à extrema metamorfose da vida matável e insacrificável do homo sacer" (AGAMBEN, 2007, p. 147-148). Desse modo, o programa de eutanásia do Terceiro Reich se consagrou como um mecanismo capaz de isolar a vida sacra do organismo social, removendo brutalmente o zoé do bíos. Este exercício de isolar e eliminar a vida que não merece viver se reproduz constantemente no âmbito do Estado, desvinculado do delírio totalitário, mas, ainda de maneira ardilosa e impetuosa. Levando em conta esta discussão, compreende-se que o conto Carta a uma senhorita em Paris, por meio de artifícios imagéticos e idiomáticos, conjura, no corpo do protagonista, a categoria política da vida indigna de ser vivida, de que falam Binding e Hoche.

\section{O suicídio em Cortázar como fundamento da soberania}

O desfecho de Carta a uma senhorita em Paris revela um processo cujo objetivo está na completa desvalorização da vida. Nesta perspectiva, lêse o suicídio do protagonista não meramente como a simples manifestação do seu desespero, decorrente da circunstância extraordinária à qual se vê relacionado, mas também como a ardilosa instrumentalização da autoagressão, motivada pela máquina antropológica para a manutenção das estruturas que determinam o conceito de humano.

A cena final do conto, narrada em um ritmo de discreta indiferença, denota o desprendimento do personagem central frente à existência. Incutido por uma culpa insuportável, ele define seu ato suicida:

Então está o amanhecer e uma fria solidão na qual cabem a alegria, as recordações, você e talvez tantos 
outros. Está esta sacada sobre Suipacha cheia de aurora, os primeiros sons da cidade. Não acho que seja difícil juntar 11 coelhinhos salpicados sobre os paralelepípedos, talvez nem os notem, atarefados com o outro corpo que convém levar logo, antes que passem os primeiros colegiais. (CORTÁZAR, 1986, p. 32).

Com essa intenção, também pondera sobre as implicações da sua morte, a maioria ínfima, exceto pelo transtorno que a destruição do apartamento causaria a Andrée: "Não tive tanta culpa, você verá quando chegar que muitos dos destroços estão bem reparados com a cola que comprei em uma casa inglesa, eu fiz o que pude para evitar-lhe um desgosto..." (CORTÁZAR, 1986, p. 32). Assim, leva-se a crer que o personagem cumpre com sua resolução mórbida, motivado pela sensação de não pertencimento àquela ordem, além de acreditar que as ocorrências no apartamento sejam da sua absoluta responsabilidade.

As tensões ocorridas no conto confluem para uma espécie de cerco ao personagem, sem rosto e identidade. A história da carta, em termos filosóficos e sociológicos, corresponde à idealização da máquina antropológica para captura e exclusão do não humano. Esta construção pressiona a contiguidade homem/animal a tal ponto que não resta alternativa ao protagonista além do próprio extermínio. Logo, a ação contínua de regurgitar coelhos, que desestabiliza o registro formal da realidade, tornase imperdoável na concepção da máquina antropológica. A narrativa, então, se envereda por uma nova camada do debate biopolítico: o suicídio como uma prática do poder soberano para cercear "a vida indigna de ser vivida" (AGAMBEN, 2007, p. 144).

Ainda que os autores Binding e Hoche não tenham conseguido o propósito de instituir cidadania jurídica à vida indigna de ser vivida, o tema levantado por eles é primordial para assinalar que o poder soberano do status quo é determinante na modernidade. Por esta razão, estabeleceu- 
se paralelos entre as interpretações de Agamben acerca do ensaio supracitado, de 1920, ao tema da vida indigna de ser vivida, no conto em estudo, Carta a uma senhorita em Paris. Nesse sentido, a narrativa de Julio Cortázar manifesta a concepção dessa existência empurrada para o aniquilamento, em razão da progressiva degradação que o devir-animal causa ao protagonista. Percebe-se, assim, o valor se esvaindo da existência do personagem central conforme sucede a emergência dos coelhos:

Quanto a mim, do dez ao onze há como um vazio insuperável. Você vê: dez estava bem, com um armário, trevo e esperança, quantas coisas se podem construir. Mas não com onze, porque dizer onze é certamente dizer doze. Andrée, doze que será treze. Então está o amanhecer e uma fria solidão na qual cabem a alegria, as recordações, você e talvez tantos outros. Está esta sacada sobre Suipacha cheia de aurora, os primeiros sons da cidade. Não acho que seja difícil juntar onze coelhinhos salpicados sobre os paralelepípedos, talvez nem os notem, atarefados com o outro corpo que convém levar logo, antes que passem os primeiros colegiais. (CORTÁZAR, 1986, p. 32).

O espaço da narrativa representa exemplarmente o controle biopolítico sobre a realidade mediante uma lógica de distribuições, pois todos os elementos estão inseridos em um rígido sistema de classificações e hierarquias. Cada objeto possui lugar e função inalteráveis neste meio, como parte de uma rígida ordem:

Para mim é duro entrar em um ambiente onde alguém que vive confortavelmente dispôs tudo como uma reiteração de sua alma, aqui os livros (de um lado em espanhol, do outro em francês e inglês), ali os almofadões verdes, neste exato lugar da mesinha, o cinzeiro de cristal que se parece com uma bolha de sabão, e sempre um perfume, um som, um crescer de 
plantas, uma fotografia do amigo morto, um ritual de bandejas com chá e pinças de açúcar... Ah, querida Andrée, que difícil opor-se, embora aceitando-a com inteira submissão do próprio ser, à minuciosa ordem que uma mulher instaura em sua agradável residência (CORTÁZAR, 1986, p. 21).

Por sua vez, a construção do personagem de Carta a uma senhorita em Paris o torna alvo da máquina antropológica, tendo em vista que ele recai na esfera do matável em decorrência da febril proximidade entre homem e animal. $\mathrm{O}$ fato de o personagem regurgitar coelhos por si só indicia uma transgressão contra a lógica que rege o universo da casa, o que deve ser sumariamente reparado. Devido a essa tensão, o poder da máquina antropológica se manifesta. Como uma entidade que se efetiva na história, imprime sua força sobre a sensação de não pertencimento, experimentado pelo personagem, naquele ambiente. Ao herói-vítima, pesa o reconhecimento da inconformidade: “[...] me desagrada entrar em uma ordem fechada, construída até nas mais finas malhas do ar, essas que em sua casa preservam a música da lavanda, o adejar de um cisne, o jogo de violino e viola no quarteto de Rará [...].” (CORTÁZAR, 1986, p. 21). Consequentemente, experimenta um sentimento de culpa a impulsionálo à autoagressão. Assim, a máquina antropológica investe contra o personagem, valendo-se da sua autoridade perante os corpos matáveis.

Os empreendimentos da máquina antropológica, realizados com o escopo de capturar e excluir o personagem de Cortázar, caracterizamno como uma vida indigna de ser vivida. Desse modo, o suicídio se desvincula do debate ético, adentrando ao cerne político, pois a decisão sobre a morte do personagem ocorre muito antes de ele visualizar esse ato como possibilidade de libertação. A máquina insere o pensamento culposo no inconsciente do personagem no início da narrativa e nas primeiras impressões sobre o apartamento a ocupar. Assim, surge-lhe o constrangimento por fazer-se presente em um espaço de direitos. 
O desfecho do conto, então, comunica acerca do desenlace de um processo de desvalorização da vida, posto que todas as tensões se encaminham para esta crise, oportunizando o aniquilamento da vida indigna, que habita o corpo do protagonista. Nesse sentido, conclui Agamben: "A vida, que, com as declarações dos direitos, tinha sido investida como tal do princípio de soberania, torna-se agora ela mesma o local de uma decisão soberana" (AGAMBEN, 2007, p. 149). Visto isso, o poder soberano delibera sobre o estado de exceção e a vida indigna. Fatalmente, a declaração: "Não acredito que lhes seja difícil juntar onze coelhinhos salpicados sobre os paralelepípedos, talvez nem os notem, atarefados com o outro corpo que convém levar logo, antes que passem os primeiros colegiais [...]” (CORTÁZAR, 1986, p. 32), informa sobre a vitória da máquina antropológica.

\section{Considerações finain}

A leitura do conto Carta a uma senhorita em Paris trouxe à tona considerações relativas às políticas que atravessam os corpos e as subjetividades da era contemporânea. Ao analisar tais políticas, ensejouse, portanto, tomar conhecimento da esfera do matável, interpretada como o espaço de exceção onde recaem os corpos que não estão de acordo com o conceito de humano, elaborado pela máquina antropológica.

Para tanto, esse mecanismo discrimina aspectos que legitimam a vida reconhecida como humana, tendo em vista raça, etnia, sexualidade, linguagem, racionalidade e integridade genética. Aplicando essa fórmula aos corpos, a máquina antropológica consegue separar da sua matéria ideológica o não humano, retirando dele a dignidade e o degredando aos territórios da matabilidade. Seguindo nesta perspectiva, pôde-se observar o protagonista de Carta a uma senhorita em Paris adentrar à realidade de exceção criada pela máquina antropológica em virtude de um fato insólito 
incontornável relacionado à modalidade ficcional do gênero Fantástico - a transição do homem para o animal, do animal para o homem e a condição do humano-animal.

$\mathrm{O}$ ato contínuo de expelir coelhos, suportado pelo protagonista, direciona-o à esfera do matável, uma vez que esse hábito feérico não apenas assedia as estruturas formais do real ordinário, mas também reporta sobre uma operação imprópria ao conceito de humano produzido pela máquina antropológica. A ocorrência em questão, desenvolvida na narrativa como uma transgressão infame, inscreve o signo do sacer no personagem. Ele se torna invisível ao estado de direitos, vendo-se compelido ao confinamento para evitar represálias.

Contudo, o isolamento ao qual o personagem-redator se submeteu não o livrou do ímpeto da máquina antropológica. As forças silenciosas em ação no conto promovem a exclusão voluntária do personagem, incluindo sua vida absolutamente matável nas gramáticas da violência. Nesse cenário, a violência é patente na autoagressão, fomentada pelas tais forças silenciosas, que a máquina antropológica mobiliza.

Por sua vez, a autoagressão cometida pelo protagonista comunica uma condição de vida na qual o valor é subtraído. Nesta direção, apurouse, no ordenamento político vigente, o surgimento da vida indigna no campo de decisões soberanas, no qual está em jogo a autorização do aniquilamento. Desse modo, tal categoria política irrompe no debate como um novo desdobramento da vida nua do homo sacer, fenômeno que se iluminou mediante a presente leitura de Carta a uma senhorita em Paris.

\section{Referências}

AGAMBEN, Giorgio. Homo Sacer: O Poder Soberano e a Vida Nua. Tradução de Henrique Burgo. 2a Edição. Belo Horizonte: UFMG, 2007.

. Meios sem fim: notas sobre a política. Tradução de Davi Pessoa. $1^{\text {a }}$ 
Edição. Belo Horizonte: Autêntica, 2015.

- O aberto: o homem e o animal. Tradução de Pedro Mendes. $3^{a}$ Edição. Rio de Janeiro: Civilização Brasileira, 2017.

CORTÁZAR, Julio. Bestiário. Tradução de Remy Gorga Filho. 3a Edição. Rio de Janeiro: Nova Fronteira, 1986.

DELEUZE, Gilles; GUATTARI, Félix. Mil platôs: capitalismo e esquizofrenia. Tradução de Suely Rolnik. Vol. 4. 1ª Edição. São Paulo: Editora 34, 1997.

DERRIDA, Jacques. O animal que logo sou. Tradução de Fábio Landa. $1^{\text {a }}$ Edição. São Paulo: Unesp, 2002.

FOUCAULT, Michel. História da sexualidade: A vontade de saber. Tradução de Maria Thereza da Costa Albuquerque e J. A. Guilhon Albuquerque. Vol. 1. 13ª Edição. Rio de Janeiro: Gallimard, 1988.

. Em defesa da sociedade. Tradução de Maria Ermantlna Galvão. 4a Edição. São Paulo: Martins Fontes, 2005.

GIORGI, Gabriel. Formas comuns: animalidade, literatura e biopolítica. Tradução de Carlos Nougué. 1ª Edição. Rio de Janeiro: Rocco, 2016.

ROAS, David. A ameaça do fantástico. Tradução de Julián Fuks. $1^{a}$ Edição. São Paulo: Unesp, 2013.

Invisible bodies in Julio Cortázar: the nonhuman in the sphere of the killable

Abstract: The present study aims to focus on bodies invisible to the juridic order in Julio Cortázar's writing, from the reading of the short story Letter to a Young Lady in Paris (1986). It's based in the discussion of Giorgio Agamben about the homo sacer - figure of the archaic Roman law, unspeakable and, at the same time killable - it seeks to analyze, in the narrative of the Cortázar, the way like the non-human, therefore classified by the "anthropological machine" (AGAMBEN, 2017, p. 51), it enters the killability sphere. In this way, the man falls in the same vulnerability level as the animal, dismantling 
existing ethical borders between both of them, certified by Jacques Derrida (2002). For consequence, it understands, with Gabriel Giorgi (2016), that the life recognized as human becomes increasingly difficult to measure in the present. So, in addition to verify, in the narrative of the prose writer Cortázar, the contemporary policies that cross the protagonist's body and subjectivity, subtracting it's value, the animal is evidenced, demarcating the threshold of this exceptional reality, where life becomes killable.

Keywords: Human. Non-human. Homo sacer. Julio Cortázar.

\section{Recebido em: 28/07/2021}

Aceito em: 03/09/2021 